\title{
Automobile Tracking System Via GPS
}

\author{
Jitendra Yadav \\ Nanjing University of Science and Technology, China, Jiangsu, Nanjing
}

\begin{abstract}
The purpose of this paper is to describe a practical model for tracking mobile vehicles based on Global Positioning System (GPS) and Global System for Mobile Communication (GSM). We shall use GSM modem which is built-in in both transmitter and receiver section to receive co-ordinates from the GPS in the vehicle. The device will collect position to supervised center by the SMS (Short Message Service) or GPRS (General Package Radio Service) and can be located in the Google Earth and hence the current position of the vehicle can be known. GSM model will be controlled by a 32-bit ARM7LPC2148.
\end{abstract}

Keywords: Vehicle tracking, Vehicle monitoring, GPS, GSM, SMS, Google Earth, ARM7LPC2148

\section{Introduction}

Global Positioning System is globally used for the tracking and navigation purpose. GPS is mainly used in the military, farming, civil transportation and commercial use around the world. Here in this paper, we describe how GPS tracking system can help us find the moving vehicle. In a country with economic prosperity where people own luxury cars, car theft is uprising crime. Car theft which is one of the biggest crime, is the main concern of this paper. The latest trend of car theft involves disabling alarm system of the car or using alarm signal to dupblicate the alarm. They also tow away the car. Alternative to prevent car theft is common alarm system which nearly all cars have the system installed and also the GPS where the whereabouts of the car can be traced. The project is done for additional features in car alarm system. The device can be added to the present car alarm system without any major modification of it. Vehicle security system using SMS/GPRS is an advanced feature of the existing car security system. The project describe a practical model for routing and tracking and monitoring the mobile vehicles using GPS and GSM at low-cost. The supporting device GSM modem GM862, are controlled by 32-bit microcontroller LPC2148 implemented a new version ARM cortex M3 core. The device will collect position to supervised center by the SMS (Short Message Service) or GPRS (General Package Radio Service)[1]. A hardware device mounted on the vehicle is connected to the engine. When the vehicle is being stolen, owner of the car can control the ignition of the engine. Automobile owner can control the vehicle from his phone. And also to solve automobile theft problem in advanced economy, big citiesany nation intending to adopt the model must put in place a policy and/or law prompting all vehicle owners to fit their vehicles with GPS trackers. In addition, GPS traffic management is considered as a priority traffic management.

\section{Problem Identification}

To curb automobile theft in developed country, this paper will serve as a guideline. Through SMS car owner will get information when the alarm is triggered. The alarm is limited to the audible distance and when the owner is at far distance, the inefficient conventional car security alarm system will not be of use. Somehow, if there is another way of transmitting the alarm of the automobile to the owner that is not limited to audible range and line of sight, the system can be upgraded [8]. SMS is a good choice of communication to replace the conventional alarm, because it can be done at low-cost. Although people know GPS can provide more security for automobile, they don't apply it because the cost is so high. Cost for the gadget is too expensive. Besides that, people also must pay for monthly service.

\section{Objective of the Study}

The primary objective of the study is to provide a solution to avoid automobile stolen at the lower cost than advance security system (GPS) and also routing and tracking vehicle in a large area environment based on the Global Positioning System (GPS) and Global System for Mobile Communication).

\section{Scope of Study}

If car gets robbed it is difficult to keep track of it. With this project we can be able to track the robbed car. This helps us to get complete surveillance of our vehicle. The advantage of this system is that it is inexpensive and light weight and disadvantage is that if the authentic person does not have mobile phone on them at the time of incident, it might be late to track the vehicle because they may disassemble the vehicle[8].

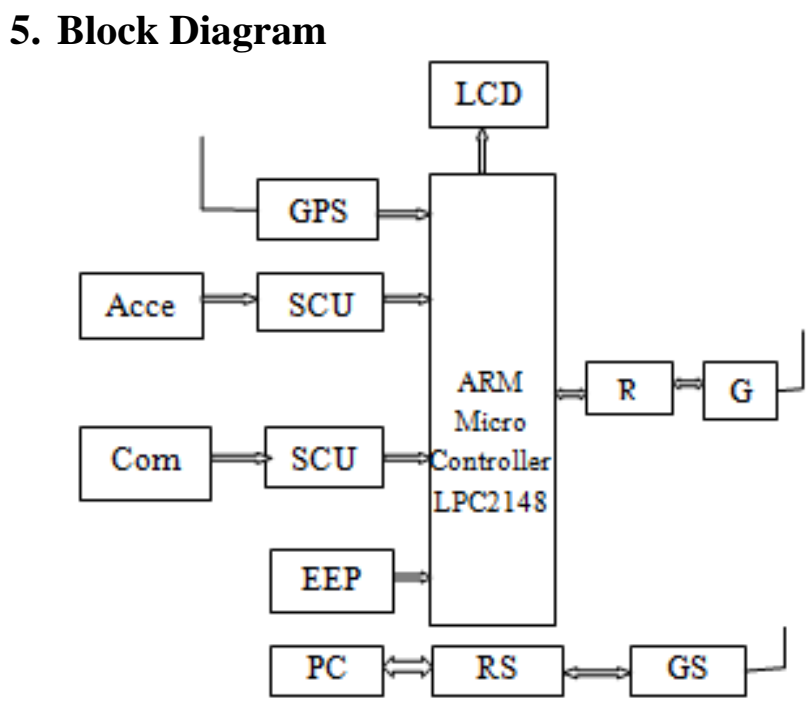

Figure 1: Block diagram

\section{Volume 6 Issue 12, December 2017}




\section{International Journal of Science and Research (IJSR)}

ISSN (Online): 2319-7064

Index Copernicus Value (2016): 79.57 | Impact Factor (2015): 6.391

\section{Work Method}

\subsection{Software Required}

Two software's were used; one for the ARM processor i.e, Embedded $\mathrm{C}$ for interfacing and controlling of different devices and in another section Visual Basic software is used for interfacing of Google Earth, so that co-ordinates can be located in the google map[3].

\subsection{Process}

Block diagram above explains the working of the system which can be designed from this paper an ARM processor LPC2148 is used here for automation and controlling of the other supporting devices those are GPS, GSM, Accelerometer sensor, Compass sensor. Actually this paper gives the practical model of a vehicle tracking system which can do routing, tracking of moving vehicles in large area. It consists of two sections, first which will be in-built in the car that is having GPS in it and as the car moves the location of the car goes on changing continuously, the GPS find the location in terms of two co-ordinates that are longitude and latitude. These co-ordinates are communicated to another section by GSM modem, as shown in the block diagram, both the part consist of GSM for communication. This GSM is connected to the computer through RS232 which should have internet connection in it. So, that as soon as the coordinates are received, it can be located in the google earth. As shown in the block diagram the two more sensors are used that are Accelerometer sensor to sense whether the vehicle is moving or steady and a Compass sensor for identifying the direction of moving vehicle[6].

\section{Terms}

\subsection{Vehicle Disabling}

Vehicle can be disabled just by sending the SMS from the GSM modem of owner to the GSM modem which is in car. The form which is generated in visual basic in the computer is connected to the GSM. If the message is send to disable the vehicle than the vehicle can be disabled. This feature is not present with the any of the vehicle security system.

\subsection{Tracking}

Tracking allows the base station to continuously track the vehicle without any interference of the driver or the method of continuously collecting the co-ordinates of moving vehicle that is getting from the GPS receiver.

\subsection{Latitude and Longitude}

Both are the angles that are uniquely defined on the sphere. Together the angle comprises the co-ordinate scheme that can locate or identify the geographic position on the planet. Latitude is defined with respect to the equatorial reference, the value becomes positive as it moves towards north and it becomes negative towards south. Longitude is measured with reference to prime meridian and is positive towards east and negative towards west.

\subsection{Routing}

Routing means a compass sensor is used to calculate the angle between the current direction of mobile vehicle and magnetic north direction.

\section{Practical Model}

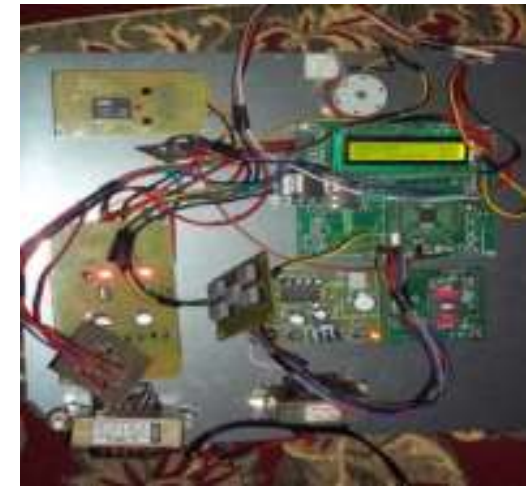

Figure 2: Transmitter Section inbuilt in the vehicle

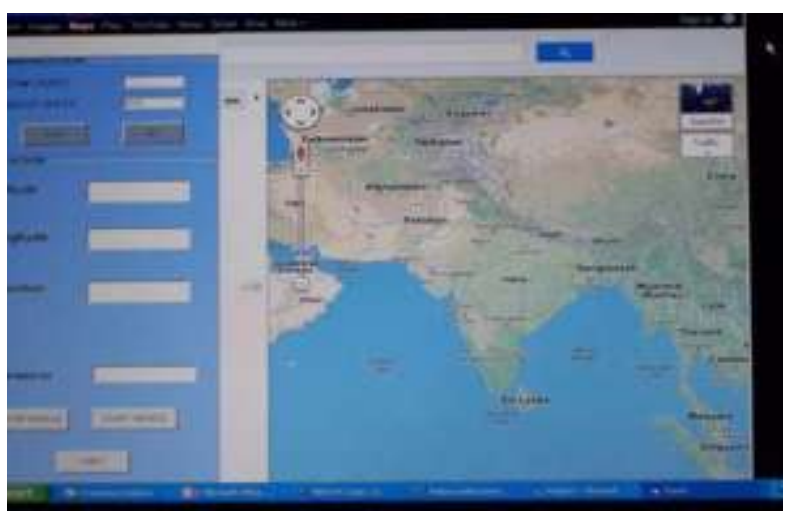

Figure 3: Receiver section with owner

\section{Result}

The results on the user interface of supervised center will show the routing and tracking function of the system. The project is locating the position of the automobile. By designing this project the ignition of the vehicle can be stopped or the speed can be locked so that the thief can be caught easily, this is one of the additional features of this project. There are some approaches that affect the accuracy of the system such as the delay of sending and receiving data via GSM network, the multi path effects can make the position error on the GPS receiver, the weather and the assuming of the variation between True North Direction and Magnetic North Direction is zero etc. 


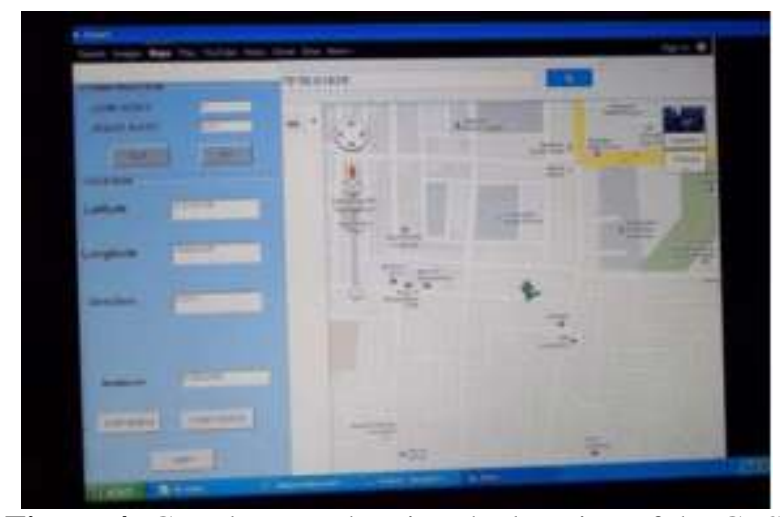

Figure 4: Google Map showing the location of the GPS

\section{Critique}

A practical system for routing and tracking mobile vehicle is presented in the project. In some cases GPS may give us no answer, the wrong answer, or the answer with insufficient accuracy which was one of the main reasons for the limitations of GPS accuracy. The accuracy of the system is affected by some factors such as weather, environment around the mobile vehicle, GPS receiver, compass sensor and the variation between True North Direction and Magnetic North Direction, etc. The future works include optimizing the hardware system, choosing a suitable GPS receiver and compass sensors and for more accuracy one can go for DGPS i.e Differential Global Positioning System, by using DGPS accuracy can be increased up to 1-4 meters whereas in GPS it is 5-10 meters.

\section{Conclusion}

Automobile theft and accidents in the transportation systems have caused significant loss of lives, waste of energy, and loss in productivity. To improve the safety, security and efficiency of the transportation systems and enable new mobile services and applications for the travelling public, the project have been developed, which apply rapidly emerging information technologies in vehicles and transportation infrastructures. It is one of the most challenging and critical issues for the industries. The practical model of this paper proved to be very efficient, cheaper, and reliable system for security.

\section{Future Work}

- The owner can switch on the digital camera recorder to record the face of the thief. This will help in identifying and capturing the thief.

- Remote door locking system to capture the thief.

- Accident detection and generating message which will inform family members about the location of accident.

\section{References}

[1] Thuong Le-Tien, Vu Phung, Vietnam "Routing and Tracking System for Mobile Vehicles in Large Area" IEEE 2010.

[2] Thuong Le-Tien, Vu Phung, Vietnam "Routing and Tracking System for Mobile Vehicles in Large Area" IEEE July 2009.
[3] Prawat Chaiprapa, Supaporn Kiattisin and Adisorn Leelasantitham "A Real-Time GPS Vehicle Tracking System Displayed on a Google-Map-Based Website. http://department.utcc.ac.th/research/images/stories/520 7003.pdf

[4] F. M. Franczyk, and J. D. Vanstone, "Vehicle warning system", Patent number: 7362239, Issue date: 22 Apr 2008.

[5] Guochang $\mathrm{Xu}$, “GPS Theory, Algorithms and Applications" Springer, 2007.

[6] Silvan Mayer, Impact of GPRS on the Signaling of a GSM- based Network, Institute of Communication Networks and Compu te $r$ Engineering, University of Stu ttgart.

[7] St ' e ph ane Piot, Security over GPRS, Master of Science

[8] Mohd Roshmanizam Bin Hamad Rodzi, "An Enhancement of Vehicle Security Alarm System via SMS, Bachelor of Science in Data Communication \& Networking, MARA University of Technology, 2006

[9] Car Security and Tracking System with Position, Route, and Speed Calculation, EDP Topic VG06, 2011

[10] Will Jenkins ,Real-time vehicle performance monitoring with data integrity, Mississippi State University 